\title{
The Influence of Thermal Comfort on the Quality of Life of Nursing Home Residents
}

Ana Mendes, Ana Luísa Papoila, Pedro Carreiro-Martins, Lívia Aguiar, Stefano Bonassi, Iolanda Caires, Teresa Palmeiro, Álvaro Silva Ribeiro, Paula Neves, Cristiana Pereira, Amália Botelho, Nuno Neuparth \& João Paulo Teixeira

To cite this article: Ana Mendes, Ana Luísa Papoila, Pedro Carreiro-Martins, Lívia Aguiar, Stefano Bonassi, Iolanda Caires, Teresa Palmeiro, Álvaro Silva Ribeiro, Paula Neves, Cristiana Pereira, Amália Botelho, Nuno Neuparth \& João Paulo Teixeira (2017) The Influence of Thermal Comfort on the Quality of Life of Nursing Home Residents, Journal of Toxicology and Environmental Health, Part A, 80:13-15, 729-739, DOI: 10.1080/15287394.2017.1286929

To link to this article: https://doi.org/10.1080/15287394.2017.1286929

Published online: 23 May 2017.

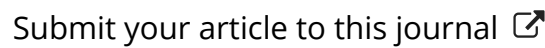

Џ Article views: 93

Q View related articles ¿

View Crossmark data $₫$ 


\title{
The Influence of Thermal Comfort on the Quality of Life of Nursing Home Residents
}

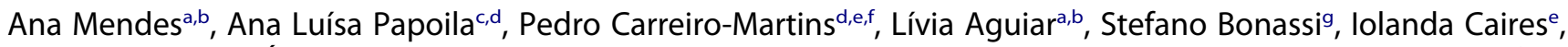 \\ Teresa Palmeiro ${ }^{\mathrm{e}}$, Álvaro Silva Ribeiro ${ }^{\mathrm{h}}$, Paula Neves ${ }^{\mathrm{a}}$, Cristiana Pereira ${ }^{\mathrm{a}, \mathrm{b}}$, Amália Botelho ${ }^{\mathrm{e}}$, Nuno Neuparth ${ }^{\mathrm{e}, \mathrm{f}}$, \\ and João Paulo Teixeira ${ }^{a, b}$

\begin{abstract}
aEnvironmental Health Department, National Health, Porto, Portugal; 'b Institute of Public Health (ISPUP), Porto University, EpiUnit Epidemiology Research Unit, Porto, Portugal; 'CEAUL, NOVA Medical School, Lisbon, Portugal; 'Epidemiology and Statistics Analisys Unit, Research Centre, Centro Hospitalar de Lisboa Central, EPE, Lisbon, Portugal; ' ${ }^{C E D O C ~-~ R e s p i r a t o r y ~ D i s e a s e s ~ R e s e a r c h ~ G r o u p, ~ N O V A ~ M e d i c a l ~}$

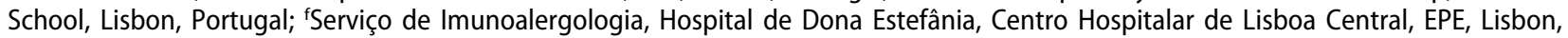

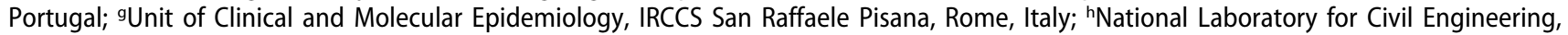
Lisbon, Portugal
\end{abstract}

\begin{abstract}
Thermal comfort (TC) parameters were measured in 130 rooms from nursing homes (NH), following ISO 7730:2005 in order to evaluate the influence of winter season TC indices on quality of life (QoL) in older individuals. Mean radiant temperature (mrT), predicted mean vote (PMV) and predicted percent of dissatisfied people (PPD) indices, and the respective measurement uncertainties were calculated using Monte Carlo Method. The WHOQOL-BREF questionnaire was conducted from September 2012 to April 2013, during the winter season TC sampling campaign. Winter PMV and PPD indices showed significant differences between seasons in median values for comfort. There were also significant differences between seasons for air temperature, air velocity, $\mathrm{mrT}$, and relative humidity. The winter PMV index displayed a "slightly cool" [ $\leq-1]$ to "cool" [ $\leq-2]$ in thermal sensation scale [ -3 to 3 ]. PPD index reflected this discomfort as evidenced by a high rate of predicted dissatisfied occupants (64\%). The influence of winter season TC on older individual QoL results demonstrated that values of PMV above -0.7 had higher mean score of QoL (coefficient estimate: 11.13 units) compared with values of PMV below -0.7 . These findings are of relevance to public health and may be useful for understanding NH indoor environment variables thus implementing preventive policies in terms of standards and guidelines for these susceptible populations.
\end{abstract}

\section{Introduction}

The World Health Organization (WHO) guidance on thermal comfort (TC) is driven to protect health against exposure to both high and low indoor temperatures. The guidance for the home environment aims to protect the health of those most susceptible and fragile to temperatures outside the comfort range, such as children and older subjects (Ormandy \& Ezratty, 2012). The European PHEWE Project (Analitis et al., 2008) reported a significant short-term increase in cardiovascular mortality of $1.72 \%$ in association with a $1^{\circ} \mathrm{C}$ fall in a 15-day average temperature (Lanzinger et al., 2014). In addition, there was also a short-term elevated risk of myocardial infarctions with a $10^{\circ} \mathrm{C}$ decrease in air temperature associated with cold temperatures (Wolf et al., 2009). Susceptible groups need to be at a minimal temperature of $20^{\circ} \mathrm{C}$ to avoid cardiovascular issues (Ormandy \& Ezratty, 2012). In this regard, thermal environment in homes does not usually produce serious illnesses; however, this factor may exert a significant impact on the general well-being and daily performance of its residents. Poor thermal environment also aggravates the influence of air pollutants on occupant's health (Mendes \& Teixeira, 2014). Over the last few decades, concern about the quality of life (QoL) in older population has increased. More specifically, health-related QoL which involves perceptions of well-being and functioning in physical, mental, social, and environment in daily life activities

CONTACT Ana Mendes asestevao@gmail.com EEnvironmental Health Department, National Health Institute Dr. Ricardo Jorge, Rua Alexandre Herculano, 321, Porto 4000-055, Portugal

(c) 2017 Taylor \& Francis 
comprises a summary quantification of perceived health issues (Costa et al., 2014). The QoL group of the WHO (Van Malderen et al., 2013) defined QoL broadly as "An individual's perception of his or her position in life in the context of the culture and value system where they live, and in relation to their goals, expectations, standards, and concerns." When studying older individuals residing in nursing homes (NH) facilities, there has been a practice to include QoL as an outcome parameter (McKee et al., 2004).

The present study examined season variations in TC parameters in $21 \mathrm{NH}$ located in Porto, Portugal, including the predicted mean vote (PMV) and predicted percent of dissatisfied people (PPD) model integrated with the QoL assessment. The main aim of this study was to evaluate the influence of winter season TC indices on older subject QoL.

\section{Materials and methods}

\section{Building characterization}

All NH located within the Porto urban area and included in the "Portuguese Social Charter" were invited to participate in our study. Out of a total of $58 \mathrm{NH}, 36 \%(\mathrm{n}=21)$ accepted to participate. A building characterization was performed by a walk-through survey including the following information: type of building construction (concrete, masonry); thermal isolation of the building envelope (type of windows and doors, the presence of weather stripping,); ventilation system (natural, mechanical, hybrid); types of indoor materials; use of gas burning appliances; evidence of dampness or mold; and ventilation practices (opened windows). Smoking was not legally allowed in any indoor location of any NH (Law 37/2007 of 14 August 2007). Outdoor relative air humidity $(\mathrm{RH})$ and air temperature (airT) were monitored using a portable monitor (GasData, model PAQ). After equipment stabilization, measurements were recorded continuously and transferred to an informatics system using PCLogger 32 V3.0 software. Outdoor monitoring was performed simultaneously to indoor thermal comfort assessment.

\section{Thermal comfort assessment}

The study was completed during winter and summer seasons, starting from November 2011 to August 2013, in $130 \mathrm{NH}$ indoor areas within common areas such as dining rooms, drawing rooms and medical offices, and private areas (bedrooms), including the bedridden subgroup. TC parameters were measured following ISO 7730:2005 (International Organization for Standardization, 2005), including variables measured in the environment, such as airT, $\mathrm{RH}$, and mean radiant temperature $(\mathrm{mrT})$ to estimate heat exchange between human body and environment, as well as, relative air speed. In order to determine PMV and PPD indices, metabolic rate and clothing insulation personal variables were taken into consideration. According to ISO 7730:2005 and confirmed by observation, elderly occupant daily activity is characterized by a metabolic rate of 1 met (seated, relaxed) and to a clothing thermal insulation of 1 clo (underwear with short sleeves and legs, shirt, trousers, jacket, socks, and shoes) in summer and of 1.3 clo (underwear with long sleeves, long trousers, long shirt, jersey, thermo-jacket, socks, and shoes) in winter. Fanger (1970, 1973) showed that men and women seem to prefer similar thermal environments. Women's skin temperatures and evaporative losses are slightly lower than those of men, and this balances the slightly lower metabolism of women (Carvalho et al., 2013).

The TC assessment was conducted in a discreet fashion in order not to disturb occupant normal life. The monitoring phase included daytime sampling (starting at $10 \mathrm{a} . \mathrm{m}$. and continuing for at least $4 \mathrm{hr}$ during normal activities). Rooms in the NH displayed homogeneous distribution of temperatures and air flows, and steady-state environment were tested according to ISO 7726 (International Organization for Standardization, 1998) specifications with TSI 8386A-M-GB thermo-anemometer. Moderate environments (class C-comfort standard) were considered. Objective physical data, including airT, mrT measured using a black-globe thermometer, RH, and air velocity, were collected by Delta Ohm HD 32.1-Data logger, placed at a height of 0.6 $\mathrm{m}$ above the floor (sitting-abdomen level). All monitoring data were collected as close as possible to the center of the room, with the sampling points no closer than $1 \mathrm{~m}$ to a wall, a window, a door or an 
active heating system. After 25 min of equipment stabilization in each room, measurements were recorded over $10 \mathrm{~min}$, sampling data each $15 \mathrm{sec}$ (International Organization for Standardization, 2005) (a total of 40 measures per room). Data for each room were obtained using the software DeltaLog10 version 1.30. The PMV and PPD indices were computed using results acquired from experimental measurements performed in the building, including metabolic rate and clothing insulation occupant factors. Results were compared to Table A.1 (Categories of thermal environment) from Annex A of ISO 7730 (International Organization for Standardization 2005).

\section{Environmental data quality assurance and quality control}

PMV and PPD indices, mrT, and their measurement uncertainties (Table 1) were calculated by Monte Carlo Method using MatLab R2013b software (MathWorks Inc., Natick, MA, United States). Expanded uncertainty was evaluated for $95 \%$ confidence intervals based upon probability distributions propagation of measures obtained by multiple samples and considering instrumental uncertainty obtained from traceable calibrations. This investigation was performed by the Environmental Health Department of the National Health Institute using methodologies accredited by NP EN ISO/IEC 17025:2005, "General requirements for the competence of testing and calibration laboratories."

\section{Questionnaires}

In each $\mathrm{NH}$, the Portuguese version of the WHOQOL-BREF questionnaire (World Health Organization, 2004; Bobic et al., 2009; Vaz Serra et al., 2006) was conducted from September 2012 to April 2013, during the winter season TC sampling campaign. The questionnaire was administered by a trained interviewer to older individuals who provided their informed consent and were able to participate.

The WHOQOL-BREF questionnaire instrument is a 26-item version of the WHOQOL-100 assessment. The Portuguese version (Vaz Serra et al., 2006) of the WHO QoL WHOQOL-BREF questionnaire was used for this purpose (Ribeiro et al, 2007). This version focused on the QoL definition advocated by the WHO, which includes the culture and context that influence individual's health perception. The questionnaire comprises 24 core items organized into four domains: physical health (7 items), psychological health (6 items), social relationships (3 items), and environmental health ( 8 items). These four domain scores denote an individual's perception of QoL in each particular domain. There are two

Table 1. Nursing Homes Thermal Comfort Parameters: Descriptive Statistics by Season.

\begin{tabular}{|c|c|c|c|c|c|c|}
\hline & $N$ & Median $\left[\mathrm{P}_{25}-\mathrm{P}_{75}\right]$ & Min-Max & $p$ & \multicolumn{2}{|c|}{ References } \\
\hline \multicolumn{7}{|c|}{ Air temperature $\left({ }^{\circ} \mathrm{C}\right)$} \\
\hline SUMMER & 68 & $23.8[21.2-25.7]$ & {$[15.9-32.8]$} & 0.05 & \multicolumn{2}{|c|}{ Summer $[22,8-26,1]$} \\
\hline WINTER & 62 & $20.3[17.9-21.7]$ & {$[15.8-23.8]$} & & \multicolumn{2}{|c|}{ Winter $[20,0-23,6]^{\mathrm{g}}$} \\
\hline \multicolumn{7}{|c|}{ Relative humidity (\%) } \\
\hline SUMMER & 68 & $53.9[38.9-62.0]$ & {$[24.0-75.2]$} & 0.05 & \multirow{2}{*}{\multicolumn{2}{|c|}{$[30-65]^{h)}$}} \\
\hline WINTER & 62 & $46.8[34.8-59.2]$ & {$[19.7-77.7]$} & & & \\
\hline \multicolumn{7}{|c|}{ Air velocity $(\mathrm{m} / \mathrm{s})$} \\
\hline SUMMER & 68 & $0.02[0.01-0.07]$ & {$[0.01-0.75]$} & 0.05 & \multirow{2}{*}{\multicolumn{2}{|c|}{$<0.25^{\mathrm{h}}$}} \\
\hline WINTER & 62 & $0.01[0.01-0.02]$ & {$[0.01-0.27]$} & & & \\
\hline \multicolumn{7}{|c|}{ Mean radiant temperature $\left({ }^{\circ} \mathrm{C}\right)$} \\
\hline SUMMER & 68 & $24.2^{\mathrm{a}}[21.5-28.9]$ & {$[15.5-33.1]$} & \multirow[t]{2}{*}{0.05} & \multirow{2}{*}{\multicolumn{2}{|c|}{-}} \\
\hline WINTER & 62 & $20.5^{\mathrm{b}}[18.1-22.1]$ & {$[15.6-27.8]$} & & & \\
\hline \multicolumn{7}{|l|}{ PMV } \\
\hline SUMMER & 68 & $-0.2^{c}[(-0.7)-0.5]$ & {$[(-3.0)-2.3]$} & \multirow[t]{2}{*}{0.05} & \multirow[t]{2}{*}{ Category } & $\mathrm{A}[-0.2 ; 0.2]$ \\
\hline WINTER & 62 & $-1.8^{\mathrm{d}}[-2.4-(-1.1)]$ & {$[(-3.0)-(-0.3)]$} & & & $\begin{array}{l}\mathrm{B}[-0.5 ; 0.5] \\
\mathrm{C}[-0.7 ; 0.7]\end{array}$ \\
\hline \multicolumn{7}{|l|}{ PPD (\%) } \\
\hline SUMMER & 68 & $11.3^{\mathrm{e}}[6.5-35.1]$ & {$[5.0-99.1]$} & \multirow[t]{2}{*}{0.05} & \multirow[t]{2}{*}{ Category } & $A<6^{i}$ \\
\hline WINTER & 62 & $64.4^{f}[31.8-90.2]$ & [6.8-99.2] & & & $\begin{array}{l}B<10 \\
C<15\end{array}$ \\
\hline
\end{tabular}

${ }^{\mathrm{a}} \mathrm{U}_{95 \%}=0.16 ;{ }^{\mathrm{b}} \mathrm{U}_{95 \%}=0.16 ;{ }^{\mathrm{c}} \mathrm{U}_{95 \%}=0.06 ;{ }^{\mathrm{d}} \mathrm{U}_{95 \%}=0.09 ;{ }^{\mathrm{e}} \mathrm{U}_{95 \%}=0.9 ;{ }^{\mathrm{f}} \mathrm{U}_{95 \%}=3.3 ;{ }^{\mathrm{g}}$ ASHRAE 55; ${ }^{\mathrm{h}}$ IAQA 01-2003; ISO 7730:2005. 
additional items, intended as indicators of overall QoL and health perception. Domain scores are scaled in a positive direction (higher scores denote higher QoL). The mean score of items within each domain is used to calculate the raw domain score. Then, two transformations methods are used: The first one converts domain raw scores to range between 4 and 20 and the second converts domain scores to a $0-100$ scale. Considering the 4-20 scale, the midpoint where QoL is judged to be neither good nor poor is 12 (Skevington et al., 2004) (which correspond to 50 in the $0-100$ scale). In the present study, the $0-100$ scale was considered. In the analysis, only the WHOQOL-BREF questionnaires with less than $20 \%$ of missing answers were considered.

Along with the WHOQOL-BREF questionnaire, a general sociodemographic questionnaire and two well-known cognitive and depression validated questionnaires were applied to perform a thorough characterization of the elderly population: (i) the Mini Mental State Examination (MMSE) used to evaluate cognitive status (Folstein et al., 1975). It is an easy to administer questionnaire, which allows cognitive function assessment in temporal and spatial orientation, calculation, memory, verbal, and written skills. The maximum score is 30 . Considering the education level (Ribeiro et al., 2007), the cutoff values for Portuguese population indicative of cognitive impairment are as follows: $\leq 15$ (for illiterates), $\leq 22$ (for those with one to 11 years of schooling), and $\leq 27$ (for people with more than 11 years of schooling).

(ii) Geriatric Depression Scale (GDS-15) used to evaluate the depression status (Yesavage et al., 1982-1983; Barreto et al., 2003). In GDS-15, each positive answer on items 2 to $4,6,8$ to $10,12,14$, and 15 is allocated one point. In turn, each negative answer on items $1,5,7,11$, and 13 is also given one point. Considering the Portuguese population, interpretation is the following: more than 5 points and less than 10 is considered suggestive of depression and more than 10 points is considered indicative of depression.

This study was approved by the Ethics Committee and the Portuguese Data Protection Authority. In order to participate in the study, the elderly were required to be at least 65 years old, had been living in the $\mathrm{NH}$ for more than two weeks, have cognitive and interpretative skills to receive the QoL questionnaire, and sign the informed consent.

\section{Statistical analysis}

An exploratory analysis was carried out for all variables. Categorical data were presented as frequencies and $\%$, and continuous variables as median and inter-quartile range (25th percentile-75th percentile) or range (min-max). Due to the fact that most of the rooms were not the same in both seasons, the two samples (summer and winter) were considered to be independent. Mann-Whitney and KruskalWallis tests were used to compare seasonal effects assessment because of the existence of outliers, high variability, and skewed distributions. The outcome QoL variables were the physical health, psychological health, social relationships, and environment WHOQOL-BREF domains in a $0-100$ scale. Mixed effects linear regression models were used to study the winter associations between the QoL domains and winter season PMV index (categorized within $[-0.7 ; 0.7]$ and outside the comfort categories). The $95 \%$ confidence intervals (CI) were also calculated. A 0.05 level of significance was used for all analyses. Data were analyzed using IBM SPSS 21.0 (SPSS, Inc., Chicago, IL, USA) and STATA 12.0. (StataCorp LP, Stata Statistical Software; TX, USA).

\section{Results}

\section{Nursing homes}

The $21 \mathrm{NH}$ were located in the city center of Porto with $78 \%$ of them in areas of heavy traffic. A total of 668 older people resided in these facilities with a range from 7 to 136 occupants per building. As regards construction characteristic, $64 \%$ were an adaptation to $\mathrm{NH}$ of an existing residential building, and $42 \%$ also had day center activities for non-residents older subjects. Most of the $\mathrm{NH}$ were built in stone masonry construction (46\%) with single pane windows (87\%). Only $31 \%$ had roof and walls insulation and half of the sampled buildings presented condensation and infiltration along walls and roofs inside the buildings. Most of $\mathrm{NH}$ (91\%) presented mixed ventilation (natural ventilation in the rooms 
along with exhaustion systems in the kitchen and bathrooms), while $9 \%$ had only natural ventilation in all indoor areas. There were no cooling systems apart from some passive measures, such as blinds and curtains on the windows. During monitoring, the mean daily ambient airT in Porto was $17^{\circ} \mathrm{C}\left[11-23^{\circ}\right.$ C], with $49 \%$ [18-80\%] $\mathrm{RH}$ in the winter, and $24^{\circ} \mathrm{C}$ [17-34 ${ }^{\circ} \mathrm{C}$ ] with $47 \%$ [18-76\%] $\mathrm{RH}$ in the summer.

\section{Thermal comfort assessment scenario}

Table 1 presents the overall results of TC in the $\mathrm{NH}$ by season. These results showed median levels of airT, RH, and air velocity within the reference limits. Still minimal and maximal levels of airT and $\mathrm{RH}$ exceeded the recommended range. Regarding the TC indices, median summer PMV presented values within the ISO 7730 category A $[-0.2 ; 0.2]$, while summer PPD presented median results in category $\mathrm{C}(<15 \%)$. The winter results for PMV and PPD indices showed median values outside the standardized range for comfort. This event may be due to lack of insulation (31\%) in the $\mathrm{NH}$ buildings failing to protect residents from the outdoor temperature variations during winter season. Further, there were also significant differences for all TC parameters between seasons (Table 1). The winter PMV index demonstrated a "slightly cool" $[\leq-1]$ to "cool" $[\leq-2]$ thermal sensation scale $[-3$ to 3$]$. The winter PPD index reflected this discomfort with a high rate of predicted dissatisfied occupants (64\%).

When analyzing the median results by room and season (Table 2), the dining room was the

Table 2. Thermal Comfort Descriptive Statistics by Room \& Season.

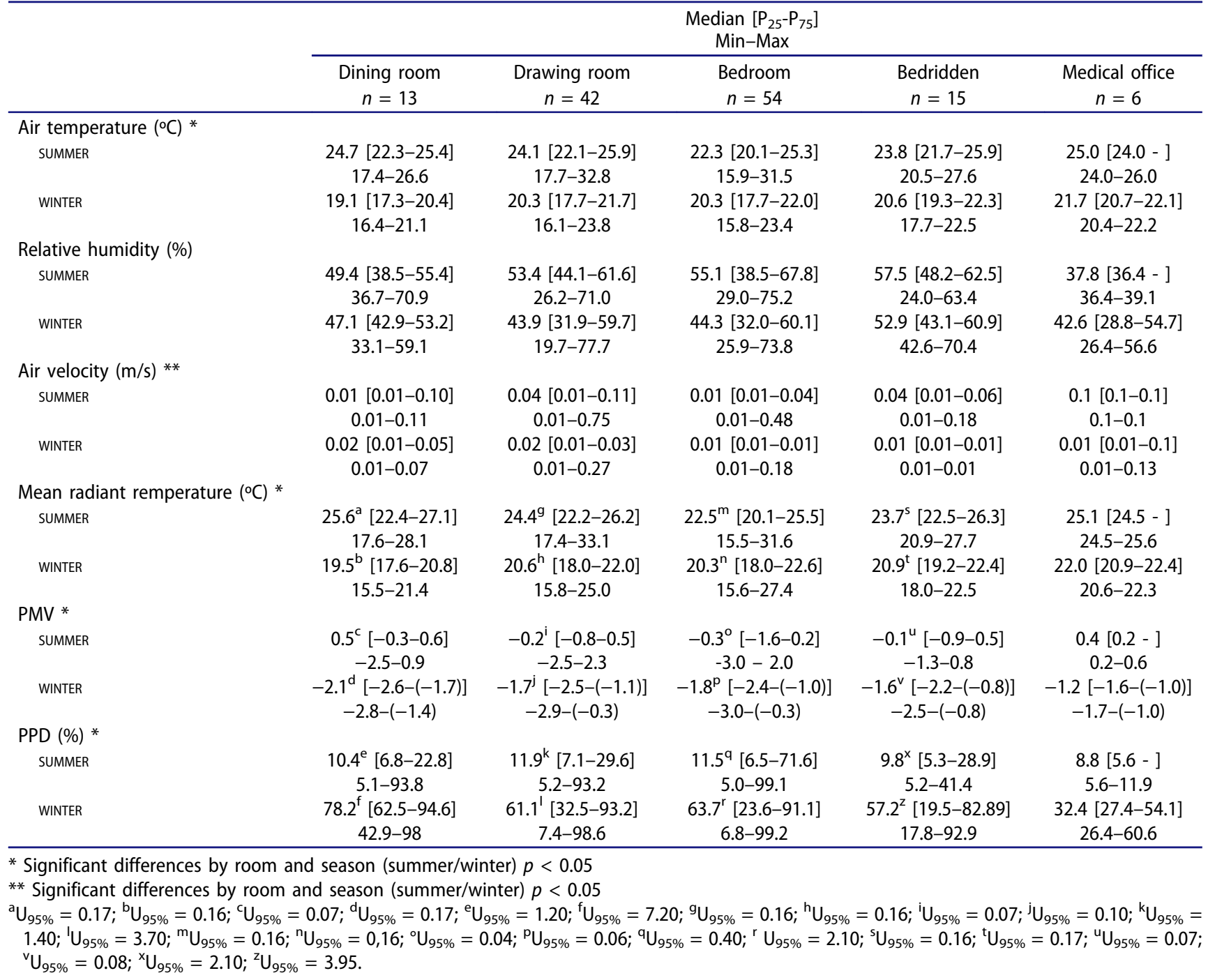




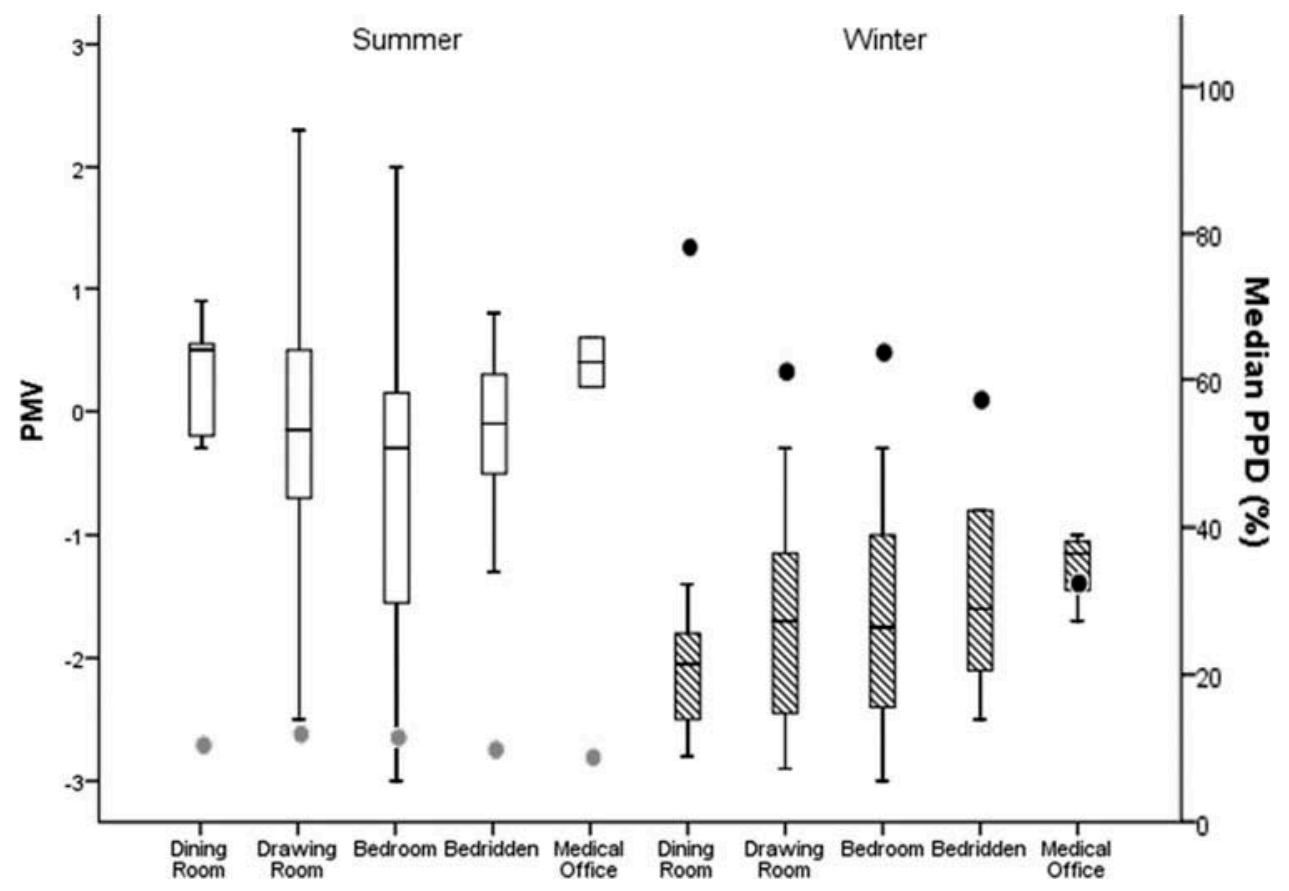

Figure 1. PMV indices (boxplots) and median PPD (dots) by room and season.

area with lowest airT and $\mathrm{mrT}$ in winter season, possibly due to this room enclosed characteristics and occupancy only a few hr a day, opposite to the bedroom which was warmest. In terms of RH and air velocity both in summer and winter season, median results in all areas were within the references. Concerning PMV and PPD indices, summer results were within the comfort categories. However, winter results presented all values outside the reference values for PPD index and PMV indices between "slightly cool" $[\leq-1]$ and "cool" $[\leq-2]$ in the 7-point thermal sensation scale (International Organization for Standardization, 2005). The rooms with lower median of PMV were the dining rooms $(-2.1)$ followed by bedrooms $(-1.8)$. There were also significant differences for airT, air velocity, mrT, PMV, and PPD indices between seasons in each type of room. Figure 1 presents graphically the season differences found in the PMV index. The summer season PMV median values in the different studied rooms ranged between +1 (slightly warm) and -1 (slightly cool) in the thermal sensation scale, including the " 0 " (neutral) where thermal balance is obtained, and internal heat production in the body is equal to loss of heat to the environment. In contrast, in the winter season results demonstrated median values of PMV between -1 (slightly cool) and -2 (cool) and interquartile range $\left(\mathrm{P}_{75}-\mathrm{P}_{25}\right)$ between -1 and -3 (cold) (Figure 1). These values were exceeded the categories for comfort and its range excluded the thermal balance (neutral).

Figure 1 also presents summer season PPD indices within the references with category $\mathrm{B}$ in bedridden rooms and medical offices, and category $\mathrm{C}$ for dining rooms, drawing rooms, and general bedrooms. The PPD winter indices showed higher rates of predicted dissatisfied occupants between twofold the category $\mathrm{C}$ referential $(<15 \%)$ in the medical offices up to fivefold higher than this same level in the dining rooms.

\section{Quality of life outcomes}

From the 668 older people living in the studied $\mathrm{NH}, 21 \%(\mathrm{n}=143)$ were within the inclusion criteria and agreed to answer the QoL questionnaire. Concerning the non-eligible (79\%), these were mostly women (62\%), 53\% lived in the $\mathrm{NH}$ in between 2 and 10 years, and 46\% were more than 85 . The main reasons to not participate in the study were disability, disease compromising the cognitive and interpretative skills to answer the questionnaire (60\%), refusal (32\%) and to be 
younger than $65(8 \%)$. The sample is characterized mainly by women (85\%) with most individuals in the age group above $85(47 \%)$. Most of the residents (61\%) had an observed degree of physical impairment and mobility (use of mobility aids such as crutches, canes and wheelchairs) or were bedridden. In the surveyed sample, $40 \%$ presented MMSE cognitive impairment and 35\% a GDS-15 score indicative or suggestive of depression. The description of the sample is presented in Table 3.

Table 4 presents the QoL status of the studied sample population according to the WHOQOLBREF. The median scores of all domains were above the 50 cutoff point. The \% scores below the cutoff point were higher in the domain 1 -physical health (29\%) followed by the domain 2-psychological health (24\%). The domain 4 environment displayed the lowest \% scores below the cutoff point (7\%).

\section{Influence of thermal comfort in older people quality of life}

Previously, Table 1 and 2 showed only negative PMV values in the thermal sensation scale for the winter season TC assessment. In this context, the winter season was considered the worst case scenario by

Table 3. General Descriptive of the Elderly Subjects $(n=143)$.

\begin{tabular}{|c|c|}
\hline & $n(\%)$ \\
\hline \multicolumn{2}{|l|}{ Gender } \\
\hline Female & $121(84.6)$ \\
\hline Male & $22(15.4)$ \\
\hline \multicolumn{2}{|l|}{ Age group } \\
\hline [65-75] & $19(13.2)$ \\
\hline [76-85] & $57(39.9)$ \\
\hline$>85$ & $67(46.9)$ \\
\hline \multicolumn{2}{|l|}{ Years living in the $\mathrm{NH}$} \\
\hline$\leq 1$ year & $37(25.9)$ \\
\hline$[2-10]$ & $83(58.0)$ \\
\hline$>11$ & $23(16.1)$ \\
\hline Dementia (MMSE questionnaire) * & $57(40.4)$ \\
\hline Depression (GDS15 questionnaire) ** & $49(35.3)$ \\
\hline $\begin{array}{l}\text { Impaired physical mobility and } \\
\text { bedridden }\end{array}$ & $85(61.2)$ \\
\hline \multicolumn{2}{|c|}{$\begin{array}{l}\text { * Scores greater than or equal to } 27 \text { points (out of } 30 \text { ) } \\
\text { indicates a normal cognition but need to be cor- } \\
\text { rected for educational attainment and age. Cutoff } \\
\text { points for a maximum of } 30 \text { points: Illiterate } \leq 15 \\
\text { points; one to eleven years of education:]15, 22] } \\
\text { points; above } 11 \text { years education:]22, 27] points; }\end{array}$} \\
\hline \multicolumn{2}{|c|}{$\begin{array}{l}\text { * Scores of } 0-4 \text { are considered normal, depending on } \\
\text { age, education, and complaints. Values higher than } \\
5 \text { indicate depression (the considered cutoff point } \\
\text { for a maximum of } 15 \text { points: }>5 \text { ). }\end{array}$} \\
\hline
\end{tabular}

Table 4. Descriptive of Self-Perceived QoL Status.

\begin{tabular}{lccc}
\hline & $n$ & Median $\left[\mathrm{P}_{25}-\mathrm{P}_{75}\right]$ & $\begin{array}{c}\text { \% below 50 } \\
\text { score cut point }\end{array}$ \\
\hline Overall QoL & 140 & $63[38-75]$ & 29 \\
$\begin{array}{l}\text { Domain 1 Physical } \\
\quad \text { health }\end{array}$ & 132 & $61[46-75]$ & 29 \\
$\begin{array}{l}\text { Domain 2 Psychological } \\
\quad \text { health }\end{array}$ & 139 & $66[50-75]$ & 24 \\
$\begin{array}{l}\text { Domain 3 Social } \\
\text { relationships }\end{array}$ & 101 & $75[58-75]$ & 12 \\
$\quad$ Domain 4 Environment & 108 & $69[59-75]$ & 7 \\
\hline
\end{tabular}

Scale ranging from 0 to 100: a higher score indicates a higher QoL. Cutoff point: 50 score (Skevington et al., 2004).

the research team. When applying the mixed effects models for testing the influence of winter season TC in older people QoL, the results showed weak evidence that values of PMV above -0.7 (toward zero and within the comfort categories) had higher mean score of QoL (domain 2) (coefficient estimate: 11.13 units) when compared with values of PMV below -0.7 (toward -3 and outside the comfort categories).

\section{Discussion}

Our study presented results for seasonal variation of TC assessment in $\mathrm{NH}$ and the winter season $\mathrm{TC}$ parameters influence on self-perceived QoL for older people. Our sample of buildings was mostly an adaptation to $\mathrm{NH}$ of an existing residential building. According to Idchabani et al., (2014), a well-designed building will be more efficient and less expensive than a structure renovated afterwards. In addition, most of the studied NH presented single pane windows and the absence of roof and wall insulation. These factors along with natural ventilated environments presenting condensations and infiltrations on walls and roofs inside the buildings may constitute a significant challenge to maintain a comfortable indoor environment for elderly populations, especially in winter season (Mendes et al., 2013, 2015). TC is a major issue for the elderly and can be associated with cardiomortality due to low temperatures in poor insulated houses (Raymann and Van Someren, 2008; Bokenes et al., 2011).

In our study, the winter TC results indicated concern with median PMV and PPD indices exceeding the standardized range for comfort (International Organization for Standardization, 
2005; American Society of Heating Refrigerating and Air-Conditioning Engineers, 2013) and significant differences were found for all TC parameters between seasons and rooms. In general, the elderly seemed to perceive TC differently from the young due to a combination of physical aging and behavioral differences (Hoof and Hensen, 2006; Hoof et al., 2010). These results along with decreased ability to regulate body temperature with age and reduction in the sweating activity of aged men (Hoof and Hensen, 2006) and women (Tsuzuki and Iwata, 2002) compared to younger age groups may increase the risk of respiratory tract infections in this susceptible population (Mourtzoukou and Falagas, 2007). Mourtzoukou and Falagas (2007) also reported that cold air inhalation, cold stress, lower core body temperature, and body surface produce pathophysiological responses such as vasoconstriction in the respiratory tract mucosa and suppression of immune responses, which are responsible for enhanced susceptibility to infections. In addition, the longer the duration of exposure the higher risk of infection (Simoni et al., 2003; Almeida-Silva et al., 2014). On average, older adults have a lower activity level, and thus metabolic rate, than younger individuals which is the main reason why they require higher ambient temperatures (Hwang \& Chen, 2010). In contrast, it is inferred that older people may suffer from more susceptible upper airways at low $\mathrm{RH}$ (Wolkoff \& Kjaergaard, 2007). An approximate $40 \% \mathrm{RH}$ is healthier for the eyes and upper airways than levels of $\mathrm{RH}$ below 30\%. Nevertheless, depending on the mucous membranes dryness, the optimal RH may differ for eyes and airways (Wolkoff \& Kjaergaard, 2007).

Our study showed only negative PMV values in the thermal sensation scale for the winter season TC assessment. Several studies (Hoof \& Hensen, 2006; Raymann \& Van Someren, 2008; Guedes et al., 2009, Hwang \& Chen, 2010) on older subjects suggested that physiologically and psychologically older adults preferred a warmer environment $\left(+2^{\circ} \mathrm{C}\right)$. The $20-24^{\circ} \mathrm{C}$ comfort zone is not warm enough for older adults that indicated an optimal temperature around $25.3^{\circ} \mathrm{C}$ for sedentary elderly. Moreover, measures of indoor operative temperatures (what humans experience thermally in a space) in Portuguese NH (Guedes et al., 2009) ranged between $16^{\circ} \mathrm{C}$ and $25^{\circ} \mathrm{C}$ in winter and $22^{\circ} \mathrm{C}$ and $31^{\circ} \mathrm{C}$ in summer. These findings are supported by other studies (Schellen et al., 2010; Hoof \& Westerlaken, 2013) demonstrating that elderly preferred a higher temperature in comparison with young adults.

Further, self-reported poor health was significantly associated with poor thermal comfort as described by Ormandy and Ezratty (2012) and Mendes et al. (2016). In our study, when applying the mixed effects models for testing the influence of winter season TC parameters in older individuals QoL, the results also provided evidence (although weak) that values of PMV within the comfort categories had higher values of QoL (domain 2-psychological health) compared with values of PMV outside the categories of thermal environment. Moreover, the European WHO LARES project (World Health Organization Regional Office for Europe, 2007; 2011) also found that TC-related problems such as cold indoor temperature, problems with the heating system, or inadequate insulation were mostly associated with respiratory problems in elderly over 65 years and older.

\section{Limitations of the study}

The main limitation of this study occurred due to the characteristics of the individuals living in the studied $\mathrm{NH}$ which compromised of sample size. In this sense, several older NH residents with cognitive impairments could not participate in the study. Regarding the $\mathrm{NH}$ participation rate, there were a high number of institutions that did not accept to participate in the study. Despite this, 6 of 7 parishes in the city had at least one participating NH. This is also a city study and may not generalize to other towns, villages, or rural areas. To overcome it, TC measurements were systematically obtained during periods of typical activities in the $\mathrm{NH}$, in a period of steady occupancy. For future sampling, one would recommend a larger sample size of $\mathrm{NH}$ and increased number of older people participating in the questionnaires. More studies relating indoor TC conditions in susceptible populations such as older people are welcome. 


\section{Recommendations to nursing homes regarding thermal comfort}

In order to contribute to improve the health of residents living in $\mathrm{NH}$ related to $\mathrm{TC}$, it is important to change inadequate ventilation, control thermal parameters and adjust clothing to environmental characteristics. The aeration needs to be done when there are no occupants in these divisions, preferring the lunchtime period, when residents are in the dining room. The renewed air can reach temperature equilibrium while minimizing the impact on the TC, by closing windows some time before the return of the occupants. It is also important to keep an airT of comfort, which needs to take into account the activity performed by residents: (i) in the absence of physical activity, closer to $25^{\circ} \mathrm{C}$; (ii) in the presence of physical activity, lower temperature, however, higher than $20^{\circ} \mathrm{C}$; and (iii) maintain $\mathrm{RH}$ between 25 and 55\% (Botelho and Neuparth, 2015). In the rehabilitation of old buildings and construction of new ones, bedrooms and drawing rooms need to be equipped with ventilation system. Select preferably bottom hung or tilt and turn windows, because the impact of outside air flow in the occupied zone is smaller (Viegas et al., 2015; Aelenei et al., 2015).

\section{Conclusions}

Winter indoor environment and TC have a potential influence in QoL of older subjects living in $\mathrm{NH}$ due to their susceptibility to seasonal temperature. Our study showed PMV and PPD indices median values exceeded the standardized range for comfort in the winter season. Evidence indicated "slightly cool" to "cool" PMV index in thermal sensation scale which may increase the risk of respiratory tract infections in this susceptible population. The PPD index reflects this discomfort with a high rate of predicted dissatisfied occupants. The influence of winter season TC parameters in older people QoL results demonstrated that values of PMV within the comfort categories had higher mean score of QoL compared with values of PMV outside the categories of thermal environment. Further studies are needed in order to analyze TC variables in these environments thus improving the well-being of our elderly population. The improvement measures need to be tested for consistency in the future if $\mathrm{NH}$ owners agree to implement them.

\section{Funding}

This work was supported by GERIA Project (www.geria.web node.com): PTDC/SAU-SAP/116563/2010 and a PhD Grant (SFRH/BD/72399/2010) from Foundation for Science and Technology (Fundação para a Ciência e Tecnologia - FCT) through Operational Competitiveness Programme (COMPETE) as part of the National Strategic Reference Framework. SB work was supported by a grant funded by AIRC (Associazione Italiana per la Ricerca sul Cancro).

\section{References}

Aelenei, D., Nogueira, S., Viegas, J.Cerqueira,, and Mendes, A. 2015. "On the relation between buildings characteristics and ventilation." Portugal Geriatric Study in on Health Effects of Air Quality in Elderly Care Centers, edited by J. P. Teixeira, 15-23. Portugal: Porto, Instituto de Saúde Pública da Universidade do Porto.

Almeida-Silva, M., Wolterbeek, H. T., and Almeida, S. M. 2014. Elderly exposure to indoor air pollutants. Atmos. Environ. 85: 54-63.

American Society of Heating Refrigerating and AirConditioning Engineers. 2013. ASHRAE Handbook Fundamentals: Chapter 9, Thermal Comfort. In.

Analitis, A., Katsouyanni, K., Biggeri, A., Baccini, M., Forsberg, B., Bisanti, L., Kirchmayer, U., Ballester, F., Cadum, E., Goodman, P. G., Hojs, A., Sunyer, J., Tiittanen, P., and Michelozzi, P. 2008. Effects of cold weather on mortality: Results from 15 European cities within the PHEWE project. Am. J. Epidemiol. 168: 13971408.

Barreto, J., Leuschner, A., Santos, F., and Sobral, M. 2003. Escala de depressão geriátrica: Tradução portuguesa da Geriatric Depression Scale, de Yesavage, et al. Lisboa: Grupo Estudos de Envelhecimento Cerebral e Demências.

Bobic, J., Gomzi, M., Radosevic-Vidacek, B., and KanceljakMacan, B. 2009. Association of neuroticism with sick building syndrome, quality of life and psychomotor performance. Coll. Antropol. 2: 567-572.

Bokenes, L., Mercer, J. B., MacEvilly, S., Andrews, J. F., and Bolle, R. 2011. Annual variations in indoor climate in the homes of elderly persons living in Dublin, Ireland and Tromso, Norway. Eur. J. Public Health 21: 526-531.

Botelho, A., and Neuparth, N. 2015. "Summary of Conclusions and Recommendations for Improvement in Respiratory Health in Elderly Care Centers." Geriatric Study in on Health Effects of Air Quality in Elderly Care 
Centers Portugal, edited by J. P. Teixeira. Portugal Porto, : Instituto de Saúde Pública da Universidade do Porto.

Costa, D., Hatzidimitriadou, E., Ioannidi-Kapolou, E., Lindert, J., Soares, J., Sundin, O., Toth, O., and Barros, H. 2014. Intimate partner violence and health-related quality of life in European men and women: Findings from the DOVE study. Qual. Life. Res. 24: 463-471.

de Carvalho, P. M., da Silva, M. G., and Ramos, J. E. 2013. Influence of weather and indoor climate on clothing of occupants in naturally ventilated school buildings. Build. Environ. 59: 38-46.

Fanger, P. O. 1970. Thermal comfort. Copenhagen, Denmark: Danish Technical Press.

Fanger, PO. 1973. Assessment of man's thermal comfort in practice. Br. J. Ind. Med. 30: 313-324.

Folstein, M. F., Folstein, S. E., and McHugh, P. R. 1975Minimental state A practical method for grading the cognitive state of patients for the clinician. J. Psychiatr. Res. 12: 189-198.

Guedes, M. C., Matias, L., and Santos, C. P. 2009Thermal comfort criteria and building design: Field work in Portugal. Renewable Energy 34: 2357-2361.

Hoof, J., Kort, H. S. M., Hensen, J. L. M., Duijnstee, M. S. H., and Rutten, P. G. S. 2010. Thermal comfort and the integrated design of homes for older people with dementia. Build Environ. 45: 358-370.

Hoof, J., and Hensen, J. L. M. 2006. Thermal comfort and older adults. Gerontechnology. 4: 223-228.

Hwang, R. L., and Chen, C. P. 2010. Field study on behaviors and adaptation of elderly people and their thermal comfort requirements in residential environments. Indoor Air 20: 235-245.

Idchabani, R., Garoum, M., and Lamzah, A. 2014. Thermal performance and environmental impact of residential buildings' heating in Morocco. Int. J. Sustainable Energy 33: 1-13.

International Organisation for Standardisation. 1998. ISO 7726:1998 - Ergonomics of the thermal environments. Instruments for measuring physical quantities.

International Organisation for Standardisation. 2005. ISO 7730:2005 - Ergonomics of the thermal environment Analytical determination and interpretation of thermal comfort using calculation of the PMV and PPD indices and local thermal comfort criteria.

Lanzinger, S., Hampel, R., Breitner, S., Ruckerl, R., Kraus, U., Cyrys, J., Geruschkat, U., Peters, A., and Schneider, A. 2014. Short-term effects of air temperature on blood pressure and pulse pressure in potentially susceptible individuals. Int. J. Hyg. Environ. Health 217: 775-784.

Law 37/2007 of 14 August 2007. 2007. Adopting Rules for the Protection of Citizens from Involuntary Exposure to Tobacco Smoke and Measures to Reduce the Demand Associated with Dependence and Cessation of Its Consumption. DR I series no. 156 of 14 August 2007 Portuguese Republic.
McKee, K., Downs, M., Gilhooly, M., Gilhooly, K., Tester, S., and Wilson, F. 2004. "Frailty, identity and the quality of later life." Understanding Quality of Life in Old Age, edited by A. Walker, 117-129. Berkshire: Open University Press.

Mendes, A., and Teixeira, J. P. 2014. "Sick building syndrome." Encyclopedia of Toxicology, 3rd edition, vol 4., edited by P. Wexler, 256-260. Elsevier Inc. Academic Press, the Netherlands.

Mendes, A., Papoila, A. L., Carreiro-Martins, P., Bonassi, S., Caires, I., Palmeiro, T., Aguiar, L., Pereira, C., Neves, P., Mendes, D., Botelho, M. A., Neuparth, N., and Teixeira, J. P. 2016. The impact of indoor air quality and contaminants on respiratory health of older people living in longterm care residences in Porto. Age Ageing 45: 136-142.

Mendes, A., Pereira, C., Mendes, D., Aguiar, L., Neves, P., Silva, S., Batterman, S., and Teixeira, J. P. 2013. Indoor air quality and thermal comfort-results of a pilot study in elderly care centers in Portugal. J. Toxicol. Environ. Health A. 76: 333-344.

Mendes, A., Bonassi, S., Aguiar, L., Pereira, C., Neves, P., Silva, S., Mendes, D., Guimarães, L., Moroni, R., and Teixeira, J. P. 2015. Indoor air quality and thermal comfort in elderly care centers. Urban Climate 14: 486-501.

Mourtzoukou, E. G., and Falagas, M. E. 2007. Exposure to cold and respiratory tract infections. Int. J. Tuberc. Lung Dis. 11: 938-943.

Ormandy, D., and Ezratty, V. 2012. Health an thermal comfort: From WHO guidance to housing strategies. Energy Policy, Elsevier 49: 116-121.

Raymann, R., and Van Someren, E. 2008. Diminished capability to recognize the optimal temperature for sleep initiation may contribute to poor sleep in elderly people. Sleep 31: 1301-1309.

Ribeiro, F., M. Guerreiro, and A. De Mendonca. 2007. Verbal learning and memory deficits in mild cognitive impairment. J. Clin. Exp. Neuropsychol. 29: 187-197.

Schellen, L., van Marken Lichtenbelt, W. D., Loomans, M. G., Toftum, J., and de Wit, M. H. 2010. Differences between young adults and elderly in thermal comfort, productivity, and thermal physiology in response to a moderate temperature drift and a steady-state condition. Indoor Air 20: 273-283.

Simoni, M., M. S. Jaakkola, L. Carrozzi, S. Baldacci, F. Di Pede, and G. Viegi. 2003. Indoor air pollution and respiratory health in the elderly. Eur. Resp. J. (Supplement 21 40): 15S-20S.

Skevington, S. M., Lotfy, M., and O'Connell, K. A. 2004. The World Health Organization's WHOQOL-BREF quality of life assessment: Psychometric properties and results of the international field trial. A report from the WHOQOL group. Qual. Life Res. 13: 299-310.

Tsuzuki, K., and Iwata, T. 2002 "Thermal comfort and thermoregulation for elderly people taking light exercise." Proceedings of Indoor Air 02, edited by H Levin, 647-652. Monterey, CA, USA. 
van Hoof, J., and Westerlaken, A. C. 2013. Indoor environmental criteria for older adults: ageing means business. HVAC J. (03/2013), 647-652.

Van Malderen, L., T. Mets, and E. Gorus. 2013. Interventions to enhance the Quality of Life of older people in residential longterm care: A systematic review. Ageing Res. Rev. 12: 141-150.

Vaz Serra, A., Canavarro, M. C., Simões, M. R., Pereira, M., Gameiro, S., Quartilho, M. J., Rijo, D., Carona, C., and Paredes, T. 2006. Estudos psicométricos do instrumento de avaliação da qualidade de vida da Organização Mundial de Saúde (WHOQOL-Bref) para Português de Portugal. Psiquiatria Clín. 27: 41-49.

Viegas, J. C., Aelenei, D, Papoila, A. L., Nogueira, S., Cerqueira, F., and Sobreira, C. 2015. "Ventilation strategies for indoor air quality improvement." Portugal Geriatric Study in on Health Effects of Air Quality in Elderly Care Centers, edited by J. P. Teixeira, 51-65. Portugal Porto, : Instituto de Saúde Pública da Universidade do Porto

Wolf, K., Schneider, A., Breitner, S., von Klot, S., Meisinger, C., Cyrys, J., Hymer, H., wichmann, H. E., Peters, A. and Cooperative Health Research in the Region of Ausburg
Study Group. 2009. Air temperature and the occurrence of myocardial infarction in Augsburg, Germany. Circulation 120: 735-742.

Wolkoff, P., and Kjaergaard, S. K. 2007. The dichotomy of relative humidity on indoor air quality. Environ. Int. 33: 850-857.

World Health Organization - Regional Office for Europe. 2007. Housing, Energy and Thermal Comfort. Copenhagen, Denmark. www.euro.who.int

World Health Organization - Regional Office for Europe. 2011. Large analysis and review of European housing and health status (LARES). Copenhagen, Denmark. www. euro.who.int

World Health Organization. 2004. The World Health Organization quality of life (WHOQOL)-BREF. WHOQOL group. World Health Organization, Geneva.

Yesavage, J. A., Brink, T. L., Rose, T. L., Lum, O., Huang, V., Adey, M., and Leirer, V. O. 1982-1983. Development and validation of a geriatric depression screening scale: A preliminary report. J. Psychiatr. Res. 17: 37-49. 